\title{
The relation between content and structure in language production: an analysis of speech errors in semantic dementia
}

Article

Accepted Version

Meteyard, L. and Patterson, K. (2009) The relation between content and structure in language production: an analysis of speech errors in semantic dementia. Brain and Language, 110 (3). pp. 121-134. ISSN 0093-934x doi: https://doi.org/10.1016/j.bandl.2009.03.007 Available at https://centaur.reading.ac.uk/17125/

It is advisable to refer to the publisher's version if you intend to cite from the work. See Guidance on citing.

To link to this article DOI: http://dx.doi.org/10.1016/j.bandl.2009.03.007

Publisher: Elsevier

All outputs in CentAUR are protected by Intellectual Property Rights law, including copyright law. Copyright and IPR is retained by the creators or other copyright holders. Terms and conditions for use of this material are defined in the End User Agreement. 


\section{CentAUR}

Central Archive at the University of Reading

Reading's research outputs online 
THE RELATION BETWEEN CONTENT AND STRUCTURE IN LANGUAGE PRODUCTION: AN ANALYSIS OF SPEECH ERRORS IN SEMANTIC DEMENTIA

Lotte Meteyard and Karalyn Patterson

MRC Cognition and Brain Sciences Unit, Cambridge

Correspondence to either author at

MRC-CBU

15 Chaucer Road

Cambridge CB2 7EF

meteyard@gmail.com

karalyn.patterson@mrc-cbu.cam.ac.uk 
In order to explore the impact of a degraded semantic system on the structure of language production, we analysed transcripts from autobiographical memory interviews to identify naturally-occurring speech errors by eight patients with semantic dementia (SD) and eight age-matched normal speakers. Relative to controls, patients were significantly more likely to (a) substitute and omit open class words, (b) substitute (but not omit) closed class words, (c) substitute incorrect complex morphological forms and (d) produce semantically and/or syntactically anomalous sentences. Phonological errors were scarce in both groups. The study confirms previous evidence of SD patients' problems with open-class content words which are replaced by higher frequency, less specific terms. It presents the first evidence that SD patients have problems with closed class items and make syntactic as well as semantic speech errors, although these grammatical abnormalities are mostly subtle rather than gross. The results can be explained by the semantic deficit which disrupts the representation of a pre-verbal message, lexical retrieval and the early stages of grammatical encoding.

Full Word count: 11,011

Keywords: speech errors, language production, semantic dementia, grammatical encoding, lexical retrieval, syntax, morphology, function words, closed class, semantic impairment. 
$\underline{\text { Introduction }}$

\section{Errors in Speech Production}

There is a long tradition of using naturally occurring speech errors to inform models of language production, under the assumption that such errors are constrained by components of linguistic processing (Fromkin, 1971; Cutler, 1981; Bock \& Levelt, 1994). One of the first models of speech production was based on an analysis of an extensive corpus of such errors in normal, healthy speakers (Garrett, 1984). Speech errors produced by different aphasic patient groups have formed the basis of debates about particular deficits and how they relate to the intact language system (Bates \& Wulfeck, 1989; Nickels \& Howard, 2000; Rapp \& Goldrick, 2000, Goldrick, 2006). Here we present an analysis of naturally occurring speech errors in a group of patients with a diagnosis of Semantic Dementia (SD), a progressive neurological condition. SD is a sub-type of Fronto-Temporal Dementia (FTD, Hodges \& Patterson, 2007) in which there is relatively focal atrophy of the anterior inferior temporal lobe bilaterally, though often more severe on the left (Rosen et al, 2002; Mummery et al, 2000; Galton et al, 2001; Seeley et al, 2005).

The striking feature of SD is a fairly selective deterioration of semantic information across all modalities of input and output, both verbal and non-verbal. Non-verbal manifestations of the deficit have been found in delayed copy drawing, where distinctive features are lost (e.g. the hump of the camel) and common features intrude, particularly for living things which share many attributes (e.g. a duck is drawn with four legs; Bozeat et al, 2003). Patients are poor at matching pictures of objects to their characteristic sounds as well as their names (Bozeat et al, 2000) and they show impaired use of objects, especially less common ones (e.g. a corkscrew or stethoscope, Bozeat, Lambon Ralph, Patterson \& Hodges, 2002). At mild-moderate stages, when SD patients can still perform categorisation tasks, they are better are categorising pictures at the general level (i.e. animal or non-living thing), than at the basic level (e.g. dog or bird), and better at the basic level than at the specific level (e.g. Labrador or Collie) 
(Rogers \& Patterson, 2007). Verbal manifestations of the semantic deficit are seen in impaired object naming and word-to-picture matching, such that these tests are routinely used in diagnosis (Hodges \& Patterson, 2007). In free speech, the anomia typical of SD results in open class items being replaced by more general, indefinite terms (e.g. 'thing', 'stuff' and 'place') and an increased reliance on high frequency, high familiarity items and pronouns (Bird et al, 2000).

In sum, SD presents a remarkably focused deterioration in conceptual-semantic knowledge such that specific, distinctive information is lost and expressions of knowledge become increasingly general, with better preservation of typical, familiar and highly frequent information (Patterson et al, 2006; Warrington, 1975). Given these qualities, the syndrome provides a unique opportunity to explore how a degraded semantic system (and associated lexical deficits) affect speech production ${ }^{1}$. Most models of spoken language production share the assumption that there are three distinct levels of processing. First is a level at which the pre-verbal message is generated and concepts are retrieved to express it (message generation). Second, there is an intermediate level at which lexico-semantic representations (words) are selected to express the concepts (retrieval of open class items); it is also thought that syntactic information is retrieved at this point and sentence structure is generated (closed class items and morphology). Third, phonological representations are retrieved that map onto the selected words (e.g. Bock, 1999; Garrett, 1984; Goldrick, 2006; Levelt et al, 1999; Vigliocco \& Kita, 2006). At present, all models assume cascading of information (i.e. partial information from one level can be accessed by the next) from conceptual to lexico-semantic representations, as this allows multiple candidates to be activated for a particular target (Goldrick, 2006; Levelt et al, 1999); interactivity between other levels is still a topic of much debate (Dell, 1986; Rapp \& Goldrick, 2000; Roelofs, 2004; Vigliocco \& Hartsuiker, 2002).

\footnotetext{
${ }^{1}$ Analyses of speech in Alzheimer's disease cannot rule out that errors are a product of attentional or memory impairments, rather than impaired lexical access or semantic impairments per se (Bates et al, 1995). SD represents a more selective deficit.
} 
SD speech is usually characterised as fluent and relatively normal as regards syntax and phonology. Nevertheless, reduction of morphological and syntactic complexity, relative to normal speakers, has been documented (Benedet et al, 2006; Patterson and MacDonald, 2006). If all levels of linguistic processing interact with the conceptual-semantic system, abnormalities beyond the semantic and lexical components of language should be observed in SD (Benedet et al, 2006). Alternatively, major abnormalities may only be observed for those components that directly rely on conceptual-semantic information, in particular message generation, lexical retrieval and some aspects of grammatical encoding (see below). A simple way to assay this hypothesis is through an analysis of errors produced by SD patients in conversational speech. We divide the areas of interest into four broad sections: (1) Message generation; (2) The retrieval of open class items; (3) The retrieval of free and bound closed class items; (4) Phonology.

\section{Message generation}

Before we open our mouths to speak, the message we want to convey must be at least partially generated. Message generation may include specifications of event semantics or thematic roles (i.e. an abstract marking of who did what to whom) which are then translated into syntactic constructions with phrasal categories (i.e. a subject noun verbing an object noun) during grammatical encoding (Ferreira \& Bock, 2006; Chang, Bock \& Goldberg, 2003). The message "activates a set of possible structural realizations" (Bock \& Warren, 1981, p.63; Bock, 1982) which influence syntactic assignment and interact with lexical retrieval during subsequent encoding.

For patients with SD, there is a deterioration of the conceptual-semantic information that underpins message generation. This may impact production in two ways. First, conceptual deterioration might cause problems during the generation and maintenance of structured message representations (e.g. MacKay, Burke \& Stewart, 1998) as specific information cannot be retrieved. So we might expect underspecified descriptions of events, simplified 
utterance structure, and a reliance on light verbs and pronouns that do not have an established discourse referent. The latter prediction is motivated by two studies which used Cookie theft picture descriptions, in which the narrative speech of SD patients used light terms (e.g. 'thing' and 'place') in place of specific open class words and an increased used of high frequency, high familiarity items (Bird et al, 2000; Patterson \& MacDonald, 2006). Second, conceptual deterioration may disrupt event semantics and be shown in gross syntactic errors, e.g. violations of word order or phrase structure. The issue of grammatical encoding has been largely neglected in research on SD (but see Tyler, Moss, Patterson \& Hodges, 1997; Patterson \& MacDonald, 2006), probably because patient's speech is on first impressions fluent and well formed, in contrast to the salient semantic deficit and anomia.

\section{The retrieval of open class items}

Anomia is characteristic of SD and has received substantial research attention (see Woollams, Cooper-Pye, Hodges \& Patterson, 2008, for an analysis of a large corpus of SD naming errors). We expect to see substitution and omission errors on open class items as appropriate words will be too unstable or too degraded to be retrieved successfully (Nickels \& Howard, 2000). As noted above, there is evidence that the free speech of patients with SD shows an increased use of light terms, so we will look specifically for substitution errors consisting of light verbs and what we will call light nouns (e.g. 'thing', 'stuff' and 'place').

Apart from substitution and omission, conflicts can also arise between conceptual and lexical access. The classic example is the tip-of-the-tongue state in which the concept is available but the word-form is not, much to the speaker's frustration (e.g. Brown \& McNeill, 1966; Vigliocco, Antonini \& Garrett, 1997). When such conflicts arise during production, the original structure activated by the message may no longer be feasible, and an alternative structure may have to be generated to accommodate problems with lexical access (e.g. Levelt 
\& Maassen, 1981). In SD we might expect to see the breakdown and restart of utterances (when lexical retrieval fails completely) and syntactically and semantically anomalous sentences that result from erroneous lexical items appearing in pre-activated structures (when lexical retrieval goes awry).

The selection of lexical items and the building of syntactic frames are intimately linked and, more importantly, the correct assignment of lexical items to phrasal roles (who did what to whom) involves both semantic and syntactic information. Lexico-semantic representations are assigned to particular roles (e.g. the agent of an action) according to a conceptual message; thus this assignment cannot be independent of conceptual-semantic content (Bock \& Warren, 1985; Bock, 1982). During syntactic encoding, when phrases are being built, lexicosyntactic information marks the appropriate context for a given word (Bock, 1999, Bock \& Levelt, 1994) and is likely to influence the encoding of an item's syntactic environment. Verbs are thought to dictate the argument structure of the sentences in which they appear (Levin 1993, Altmann, 2004), and Levelt et al (1999) proposed that 'lemmas' (holistic lexical representations) are marked for syntactic information (e.g. lexical class) amongst other things. For example, a selected lemma that is marked as a noun should/will not be assigned to a verb position in a syntactic frame.

It is an interesting question how the degraded semantic information in SD will affect this assignment process. The fact that syntactic information is abstracted across numerous members of a given class (e.g. all nouns, all verbs) and is probably redundantly coded (e.g. Bates \& Wulfeck, 1989) should make it at least relatively robust to lexico-semantic deficits. With this in mind, we might not expect gross phrasal violations (e.g. if the content of a specific noun is degraded, it may still be marked a noun). However, it is an open question whether other syntactic errors, with closed class items, morphology or agreement, may surface. If semantic and syntactic sources of information compete during the selection of lexical items, a reduction in the strength/reliability of semantic information might increase 
reliance on syntactic information (Gordon \& Dell, 2003). Such a trade-off should produce an augmented use of light verbs and increased errors on open rather than closed class items (Gordon \& Dell, 2003). The status of free and bound closed class items as predominantly syntactic entities has been debated for a long time, and it is here that the data from semantic dementia may be most informative.

\section{The retrieval of free and bound closed class items}

In Garrett's original model of production $(1982,1984)$ and other models since (e.g. Levelt et al, 1999; see also Gordon \& Dell, 2003), open class items are activated by conceptualsemantic information and then inserted into syntactic frames built around grammatical requirements, e.g. phrasal and constituent ordering (e.g. in English, Subject-Verb-Object, determiner before noun and so on), subcategorisation and tense. In contrast, grammatical morphemes (both free and bound) are activated indirectly, via open class items, and they are intrinsic to the syntactic frame (Garrett, 1982, 1984; Bock \& Levelt, 1994). It remains a topic of debate whether there is separate representation of closed class items as syntactic entities vs. open class, content words as semantic entities (e.g. Allen \& Seidenberg, 1999; Altmann et al, 2001; Biassou et al, 1997; Bradley \& Garrett, 1983; Bates \& Wulfeck, 1989; Caramazza et al, 2001; Druks \& Froud, 2002; LaPointe \& Dell, 1989). The view that closed class items are especially related to syntactic processing is also considered in explorations of agrammatism, in which special problems with these items are cited, amongst other deficits (e.g. Bates \& Wulfeck, 1989; Druks \& Froud, 2002; Mesulam et al, 2003; Milman, Dickey \& Thompson, 2008; Gordon \& Dell, 2003). Closed class items have been divided into those with some semantic content like locative prepositions (up, down, above etc.) versus those that are 'purely' syntactic, like determiners or auxiliaries, (Garrett, 1984; Levelt, 1989; Bock \& Levelt, 1994). If primarily governed by syntactic properties, closed class elements may be selected competitively once grammatical features are specified by an active lexical item; this 
would make their selection similar to open class elements that are competitively selected once semantic features are specified (Schiller \& Caramazza, 2002, 2003, 2006; Caramazza et al, 2001; Schiller \& Costa, 2006; see also LaPointe, 1985; LaPointe \& Dell, 1989). In contrast, closed class elements may be chosen once competition amongst grammatical features is resolved: in other words, competitive selection would apply to grammatical feature specifications but not to closed class elements (La Heij, Mak, Sander \& Willeboordse, 1998; Levelt, Roelofs \& Meyer, 1999; Schriefers, 1993; Schriefers, Jescheniak \& Hantsch, 2005). In both cases, the selection of closed class items depends on grammatical features activated from open class items. If closed class items are primarily syntactic, and syntax is preserved in $\mathrm{SD}$, we do not expect errors on closed class items.

Alternatively, closed and open class items could share representation and processing, but occupy different positions along crucial parameters. For example, closed class words are semantically 'shallow', having fewer semantic features than open class items, which could make them more vulnerable to damage within the semantic system or between semantics and word form representations (Allen \& Seidenberg, 1999; Goodglass \& Menn, 1985; Plaut \& Shallice, 1993). Bates \& Wulfeck (1989) point out that, in comparison to open class items, closed class items are less phonologically salient (being typically short and unstressed), less

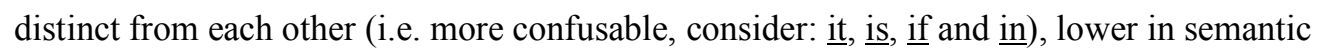
content, and given less contextual support in the sense that they appear in almost every possible semantic context. Here, the selection of closed and open class items is similargoverned by the same lexico-semantic retrieval processes - but the nature of the items makes them more or less vulnerable to semantic degradation. If this is the case, we expect to see errors on these items in SD.

In light of the different patterns of impairment in agrammatic speech for bound (substitution) and free (omission) closed class morphemes (LaPointe, 1985) and thus their possible separate retrieval processes (LaPointe \& Dell, 1989; Schiller \& Costa, 2006) it will be particularly 
interesting if SD patients show impaired use of morphology (bound closed class items). It is not clear whether a semantic impairment should disrupt one more than the other. Morphology may be preserved as bound morphemes depend on (successfully retrieved) open class items whereas free morphemes may be more vulnerable. Alternatively, both free and bound closed class items may be similarly impaired, lending weight to the view that they are retrieved by similar processes which depend to some degree on semantic information.

There are just the barest hints that SD patients might have difficulties with closed class items. In a case study, a Spanish SD patient was reported to have problems with the production of complex morphological forms (both inflectional and derivational) and tended to omit or substitute the required auxiliary or produce an active sentence when a passive was elicited (Benedet, Patterson, Gomez-Pastor \& Garcia de la Rocha, 2006). If our current (and firstever) analysis of extended segments of spontaneous speech in SD uncovers significant errors on closed-class items (free or bound or both), this could support one of two conclusions. If closed class elements are primarily syntactic in nature, the errors may be due to the degraded representation of open class items that leads to underspecified syntactic processing, which then causes problems when assigning closed class items (Levelt, 1989). For example, related phrasal verbs in English such as 'clean up' and 'clean out' may require stable semantic activation for the correct preposition to be used. Thus, if semantic information is deficient, we may expect more errors on closed class items as they are underspecified; but if open class items are successfully retrieved and produced, it is unclear why accompanying closed class elements would be underspecified. Alternatively, closed class elements may be vulnerable because of their own semantic shallowness (Allen \& Seidenberg, 1999) and increased confusability (Bates \& Wulfeck, 1989). Here, both open and closed class items undergo similar competitive selection processes governed by semantic information and both are inserted into syntactic frames. When semantic information degrades, both open and closed class items are affected. Closed class items may be less affected as they are more frequent and from a closed set (reducing the likelihood of omission), but they may also be protected by 
preserved syntactic information that governs their context of use (Gordon \& Dell, 2003;

Druks \& Froud, 2002). An error pattern in which closed class elements of all types are

affected, but those within syntactic phrases are relatively less affected, would fit with the idea that preserved phrasal syntax actively protects vulnerable closed class items. Due to the nature of the deficit in SD, we favour a parsimonious explanation in which both open and closed class items are reliant (to a different extent) on semantic information; when this information degrades, all elements become vulnerable.

\section{Phonology}

During the final stages of production, content words are serialised into their correct sequential order (constituent assembly), approximating the surface structure of the to-be-produced sentence. This stage may be driven by processes that respect phrase structure rules (e.g. SVO), realising grammatical relations established by assigning lexical items to syntactic functions (Bock \& Levelt, 1994; LaPointe \& Dell, 1989). Word forms are inserted into a serially ordered frame as are inflections (e.g. pluralizing nouns) and grammatical morphemes (e.g. auxiliaries), along with the stress contours and other prosodic features of the sentence (Garrett, 1975). Understood in this way, the frames are sensitive to phonological information, but blind to syntactic and semantic constraints (Bock \& Levelt, 1994; Garrett, 1975, 1980). For example, stem exchanges such as "she's already trunked two packs" which violate syntactic category (noun vs. verb stem) were thought to occur at this phonological stage of production (Garrett, 1975 but see Ferreira \& Humphreys, 2001; Dell, 1986;

Vigliocco \& Hartsuiker, 2002).

SD patients are, of course, profoundly anomic; but when they do manage to retrieve the name of an object or action, they almost invariably pronounce it correctly, and they are reported to make no more phonological errors in spontaneous speech than normal speakers do (Patterson $\&$ MacDonald, 2006). This may seem surprising given that, when SD patients are asked to repeat sentences or short strings of words - especially if these include items whose meaning 
the patients no longer know - they perform poorly and produce characteristic phoneme blend or transposition errors across recalled items, e.g. 'mint', 'rug' repeated back as 'rint', 'mug' (Patterson, Graham \& Hodges, 1994; Jefferies, Jones, Bateman, Lambon Ralph, 2005; Majerus, Norris \& Patterson, 2007). The patients' unaffected phonological production in spontaneous speech and their disrupted phonological production in tasks of auditory-verbal short-term memory (AVSTM) are not, however, discrepant findings. In AVSTM, especially when the phonological load is near or above span, people rely increasingly on lexicalsemantic information to aid maintenance and recall. This is why span is higher for words than non-words, and higher for high-frequency and/or high-imageability words than lowfrequency/low-imageability words (Poirier \& St-Aubin, 1996; Walker \& Hulme, 1999). When there is little or no lexico-semantic information to assist recall, the phonological trace becomes hard to maintain, and people make phonological errors. Normal people make such errors in AVSTM with nonwords but not with words (Treiman \& Danis, 1988). Despite the fact that SD patients frequently make such phonological errors in AVSTM for words, we predict that they will not make such errors in spontaneous speech. This is because a speaker is only able to produce, from the conceptual level, words with relatively stable semantic representations.

In summary, via an analysis of errors produced in the conversational speech of patients with $\mathrm{SD}$, we hope to inform debates on the relative independence/interdependence of syntactic and semantic processing, particularly during grammatical encoding. We predicted a disruption of message generation and clear evidence of anomia, in line with the idea that degraded conceptual-semantic knowledge affects lexical retrieval and the maintenance of coherent message level representations. Furthermore, on the assumption that closed class items are semantically shallow as well as perhaps still dependent on syntactic information, we anticipated errors with closed class items of all types. However, gross syntactic violations may not be evidenced if phrasal syntax is preserved. This would constitute the first clear evidence that syntactic errors are present in the speech of patients with SD, and support a 
separation between the building of syntactic frames and the insertion of lexical items of all kinds (open and closed) into those frames.

Method

\section{$\underline{\text { Participants }}$}

Seven patients with a clinical diagnosis of semantic dementia (SD) were recruited to take part in a study of autobiographical memory (Hornberger, Piguet \& Hodges, 2008). One other patient (DV), who was too impaired to participate in the autobiographical memory study, had his free speech recorded before routine neuropsychological testing. All patients were identified through the Memory and Cognitive Disorders Clinic or the Early Dementia Clinic at Addenbrooke's Hospital, Cambridge, UK. Their diagnosis was based on the cognitive and neuroradiological criteria outlined by Hodges et al (1992). Their mean age (at the time of completing the majority of neuropsychological tests) was 64.9 years (s.d. $=6.4)$, and they had spent an average of 13.6 years in formal education (s.d. =3.2). Eight control participants were selected from a set of fifteen recruited for the same autobiographical memory study; their mean age was 60.4 years $(\mathrm{s} . \mathrm{d} .=4.9)(\mathrm{t}(14)=2.0, \mathrm{p}=0.06)$ with an average of 15.6 years $(\mathrm{s} . \mathrm{d} .=3.2)$ in formal education $(\mathrm{t}(14)=-0.912, \mathrm{p}>0.3)$. Control participants were recruited from the MRC Cognition and Brain Sciences Unit volunteer panel. For the patients, background information and test scores on standard neuropsychological tests are given in Table 1; the patients are assessed longitudinally and the scores in Table 1 are taken from the testing session closest in time to the interview/connected speech recording. Control test scores are taken from a separate sample of controls (Hodges \& Patterson, 1995). All participants were native speakers of British English. 


\section{Connected Speech / Interview elicitation}

Each participant (apart from DV, see below) took part in a semi-structured interview (approximately 30 to 60 minutes long) using the Autobiographical Memory Interview (AMI, Levine et al, 2002; Kopelman et al, 1990; see Nestor et al, 2002 and McKinnon, Moscovitch et al, 2006 for examples of its use with SD patients). In brief, the interviewer began by describing the purpose of the interview (to talk about events from different periods of the participant's life) and then asked each person to recall specific events that happened on one day and were particularly striking or memorable. They were asked to recall events from four life periods: the teenage years (before 18 years old), between 18 and 30, between 30 and 50, and something that happened in the last year. Participants were encouraged to talk at length about a given event. Following the initial response by the participant, the interviewer attempted to prompt the recall of more specific information (by asking, for example, what people were wearing, what the participant felt at the time and whether there were any specific sensory memories - i.e. colours, sounds, smells, tastes - associated with that memory). Once the participant had produced a sufficient amount of detail or it became clear that he could not, the interview moved on to the next life period. Typical topics were weddings, births, birthdays, holidays and work related events (e.g. first job, redundancies or retirement). Interviews were typically conducted in one session, although 2 of the patients (BC and PS) had follow up interviews that reassessed information recalled in the first session; these were also transcribed and analysed. The speech sample for patient DV was opportunistically gathered from a conversation at the start of some tests, for which responses are normally recorded; this sample was approximately 8 minutes long. We include it in this analysis as DV is the most impaired patient (according to tests including the ACE, MMSE, word-to-picture matching and naming - see Table 1), therefore he represents an extreme point on the SD continuum. In addition, he produced several interesting speech errors during this brief conversation. 
Patients and controls produced a similar number of words (Control Mean $=4618$ (796), Patient Mean $=7087(1813) ; \mathrm{U}=19.0, \mathrm{z}=-1.042, \mathrm{p}>0.3)$ but controls produced significantly fewer utterances $(C=685(\mathrm{SE}=105), \mathrm{P}=1415(329) ; \mathrm{U}=9.5, \mathrm{z}=-2.143, \mathrm{p}<0.05)$; see below for details of how an utterance was defined. Thus, the Mean Length Utterance was shorter for patients $(4.8(0.3))$ than controls $(6.6(0.3) ; \mathrm{U}=1.0, \mathrm{z}=-3.125, \mathrm{p}<0.005)$; see Table 2.

\section{$\underline{\text { Transcription }}$}

Each interview was transcribed from the original recording by the first author using Express Scribe (v 4.15, NCH Swift Sound, www.nch.com.au/scribe). All recorded speech was transcribed (i.e. all conversation before, during and after the AMI). For patient DV, all conversation prior to the beginning of formal testing was transcribed.

A minimal transcription style was used, breaking the participant's speech into separate utterances along pause boundaries (any pause $>\approx 0.5$ seconds) with no punctuation, no other annotation was used. Dysfluencies (er, erm, um, uh) were transcribed. Any items that could not be confidently transcribed (e.g. inaudible items) were marked with square brackets e.g. [and] or as a question mark in square brackets e.g. [?]. Utterances with these ambiguous items were not included in further analyses, nor were phrases that appeared repetitively as idiosyncratic discourse markers or filler terms ('I mean', 'I dunno'), direct responses to questions (yes, no) or immediate repetitions of questions asked by the experimenter. The basic transcripts were then loaded into Excel and errors were extracted and coded.

A strict criterion was applied when classifying utterances as correct or erroneous. Once filled pauses and discourse markers had been removed, sentences were judged according to whether they would be considered correct had they been written (given some flexibility for dialect and conversational style). When an error was ambiguous, we erred on the side of caution and did 
not include it. Such strict scoring may seem ungenerous to the patients, in classifying as errors some utterances that would be treated as acceptable speech by more lax criteria. Where real connected speech is concerned, however, correctness is always a matter of judgement; and of course the same strict scoring was applied to the control transcripts.

To check the coding of errors, the second author evaluated the original transcripts for 2 patients (DV and $\mathrm{GH}$ ) and 2 controls, marking any errors and assigning them to error categories. Across these transcripts, there was $86 \%$ agreement. Any disagreements were resolved by discussion between the two raters.

\section{Coding}

In all the examples provided below, patients are referred to by their initials (e.g. JW, MJ) and control participants by their number assigned in the original autobiographical memory study (e.g. C1, C16). A forward slash ( / ) indicates separate utterances.

\section{$\underline{\text { General }}$}

Corrections: when an error is made and then self-corrected. For example, JW "she got married in the church / [its] not the church the hospital / she was born in a hospital";

Restarts: when a sentence is started, halted before it is completed, and restarted using either the same or a different construction to express the same message. For example, C16 "I went in / in the [mor] / I went in at one o'clock". 
$\underline{\text { Errors }}$

Phonological: All phonological errors, including phonologically related substitutions (where a 'correct' item is clearly identifiable, e.g. PS “different accidents" accents), morpheme strandings/perseverations (e.g. BC “competitions / quizzes / and karaokes as well / yes karaokes") and phoneme exchanges/ substitutions (e.g. PS “sleeving / sleeving sleeping”). This category does not include the partial production of items (i.e. incomplete words).

Omission: An item is missed but the rest of the sentence is intact. The missing item is clearly identifiable from the context (e.g. marked by a determiner if a noun, or subject if a verb). For example, PS “I mean we've been _ / forty years now" (verb: married); MJ "I can remember sitting in the _/ when we were all having the tea" (noun: room/lounge); BC "I can remember that there were lots of men playing _ the party" (preposition: at); DB "that was _ crazy thing but" (determiner: a/the).

Substitution: An item is replaced by another item. This category also includes replacement by descriptive forms such as 'air station' for airport and indefinite, light terms such as 'thing', 'place' or 'stuff' where a more specific item would be more appropriate. For example, BC “there's a like music stop competition" (descriptive substitution: musical statues); PS “where you learn other things about army stuff" (light noun); JC "we did a house up there" (light verb: bought/renovated); JW "and so we went to school / in a box near the school" (noun: building); DB "so she would help the mother" (determiner: her); MJ "I think we got married at fifty nine" (preposition: in).

Perseveration/Anticipation: An item appears out of context after or before its appearance at the grammatically correct place; e.g. BC: "and some of the parents as well were there as well" (anticipation: as well); PS "I sat her on her lap near" (perseveration \& substitution: her (my)). 
Insertion: An item is inserted incorrectly into a sentence (without perseveration or anticipation) and its removal would create a grammatical sentence; e.g. GH: "regarding to that aspect" (to).

Morphological Errors An incorrect morphological form is used (inflectional or derivational) and the 'correct' alternative can be clearly identified. These were separated into errors where the incorrect form was equally or more complex, as compared to more simple, than the correct target. Errors were also separated into those occurring on verbs and those occurring on other items (e.g. nouns, adjectives etc.). For example, MJ: "that' s made me cried a lot" (verb complex: cry); DV: "we were allowed to go in and / and they stop for a drink there" (verb simple: stopped); BC: "I like being promotions don' t I" (other complex: promoted); DB: "well he was a normal dressed individual" (other simple: normally)

Agreement Errors When two items (e.g. determiner and noun, subject and verb) disagree in inflection for number, count/mass, person (if a verb) etc. Similar to morphological errors except it is not clear which item has the 'wrong' inflection. For example, BC "walking past this toilets" (these toilets / this toilet).

\section{Planning}

These errors occur at the sentential level and are not classifiable according to the above criteria. They do not fit neatly into a particular coding strategy and, after being counted as part of the total errors, were only descriptively analysed. We feel they are still informative as regards the impact of a central semantic deficit on sentence production, but no statistical comparisons are made as classification is potentially ambiguous. To provide some structure for the description of these errors, we have broadly subdivided them into the following categories (which are not mutually exclusive): 
Sentence Blend: two (or more) identifiable alternative structures blended together e.g. BC "how I heard it from" (how I heard it / who I heard it from..").

Semantic/Syntactic Anomaly: Sentences which present a syntactic or semantic anomaly that cannot be attributed to a simple substitution or omission error, misordering or disjointed sentence (see below). Instead the initial selection of items appears disrupted. Sometimes comparable to approximations/circumlocutions (see below), except that they do not appear to have too many words (circumlocutions) or to be overly general (approximations), e.g. DB “it was folded upright".

Misordering: When a single item or phrase is in the wrong place. It must be possible to create an alternative, 'correct' sentence by re-arranging the individual items, e.g. PS "a lot of people local as well" (a lot of local people as well). These are different to perseverations/anticipations as the incorrect item does not occur in the correct place elsewhere in the sentence.

Simplification: an entire event is simplified and unelaborated, usually using a light verb and with no extra/specific information (adjectives, adverbs) that describes the event e.g. BC "big our garden".

Approximation/Circumlocution: In which an event description is approximated, rather than clearly described, either by using too many words (circumlocution) or anomalous/unclear items for that message (approximation). These sometimes also contain semantic or syntactic anomalies. e.g. GH "I effectively you know / helped with his intelligence / to mend the car". Disjointed: Sentences are disjointed across successive utterances. The errors come from sentences not being linked smoothly (with the correct conjunction terms or phrases), the production of sentence fragments or the introduction of novel/unrelated information. They cannot be explained by the omission of a single item or phrase. Therefore, some of these also contain semantic or syntactic anomalies e.g. JW "how the hell do I come up / down or not". Unreferenced pronoun: An item (usually demonstrative pronoun) does not have a discourse referent, not attributable to the patient gesturing or pointing to some object (this is usually 
clear from the transcript, as the patient will say something like 'that one over there' or 'this one here'). e.g. JC "and that went in didn't it".

We hypothesise that patients should produce more planning errors of all kinds, as they reflect problems with grammatical encoding and sentence formulation that result from difficulties in message generation and lexical retrieval.

\section{$\underline{\text { Analysis }}$}

The total number of errors and restarts were divided by the total number of utterances for that participant. Self-corrections were divided by the total number of errors. Errors isolable to individual lexical items (omissions, substitutions, perseverations, anticipations, insertions) were separated into those with open and closed class words, and divided by the total number of open and closed class words for that participant. Open class words were defined as nouns, verbs and adjectives. Temporal nouns (e.g. 'hours', 'day', 'week', 'month') and numbers were not included as it was felt that the AMI would evoke an unrepresentative number of these items. Closed class words were defined as pronouns, auxiliaries, determiners, prepositions, conjunctions, modifiers, numbers and negatives (see Appendix 1 for sub-types of these classes). Adverbs were not included in either class (being a productive class from which a small number of items were typically used, e.g. probably, quickly, slowly etc.). Morphological errors (which were found on verbs, nouns, adjectives and adverbs) were divided by the total number of words. Morphological errors on verbs were also isolated and divided by the total number of verbs. Agreement errors were divided by the total number of utterances as they occur across lexical items and classes (i.e. a determiner and noun, a subject pronoun and verb). Thus, each coded item was converted into a percentage score: total errors, restarts and agreement errors as a percentage of utterances, corrections as a percentage of errors, open class errors as a percentage of open class words, closed class errors as a percentage of closed class words, morphological errors as a percentage of total words, verb morphological errors as a percentage of total verbs. 
For omission and substitution errors, a closer analysis was made to compare the diversity and types of items that took part in these errors. Some sub-types took account of their context of use. We compared patients and controls on the number of substitutions of light nouns, descriptive nouns or noun phrases (both as a percentage of nouns) and light verbs (as a percentage of verbs). Pro-drop omissions, where the subject pronoun is dropped from the beginning of an utterance, were counted separately to other closed class omissions, and phrasal omissions (more than one identifiable consecutive item missing) were compared as a percentage of utterances. We also compared the percentage of closed class omissions and substitutions in which a preposition was omitted from a prepositional phrase (Pp) as opposed to verb sub-categorisation (Sc-p) context (see Appendix 1 for the different subtypes of open and closed class words).

All comparisons were made using Mann-Whitney U tests. The means and standard errors are given for each significant comparison, and for non-significant comparisons that are of interest. 
$\underline{\text { Results }}$

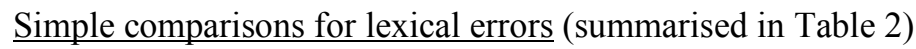

$\underline{\text { General }}$

Patients made significantly more errors (Patients $\mathrm{M}=23.8 \%$ (2.9\%), Controls $\mathrm{M}=7.0 \%$

$(0.58 \%), \mathrm{U}=0.00, \mathrm{z}=-3.361, \mathrm{p}<0.005)$ and tended to make fewer corrections (as a

percentage of errors, $\mathrm{P} \mathrm{M}=8.2 \%(1.9 \%), \mathrm{CM}=16.2 \%(4.8 \%), \mathrm{U}=22.00, \mathrm{z}<-1.2)$ than the

Controls. Patients made more errors with open class ( $\mathrm{P} \mathrm{M}=25 \%(2.8 \%), \mathrm{C} M=0.5 \%$

$(0.1 \%), \mathrm{U}=0.00, \mathrm{z}=-3.361, \mathrm{p}<0.005)$ and closed class $(\mathrm{P} \mathrm{M}=30 \%(1.9 \%), \mathrm{C} \mathrm{M}=1.3 \%$

$(0.1 \%), \mathrm{U}=0.00, \mathrm{z}=-3.361, \mathrm{p}<0.005)$ items. Patients also had significantly more restarted

utterances ( $\mathrm{P} \mathrm{M}=8.7 \%(1.7 \%), \mathrm{C} M=4.3 \%(0.88 \%), \mathrm{U}=12.00, \mathrm{z}=-2.1, \mathrm{p}<0.05)$.

\section{Phonological and Other Errors}

There was a notable absence of all the error types that we subsumed under the label of

'Phonological errors'. For the patients, there were four examples of morphological

stranding/perseveration errors (see Table 2), and no errors of this kind for the controls. There

were eight examples of phonological substitution errors in patients, all produced by one

patient, PS, some of which were spontaneously corrected; there were two substitutions and

one partial perseveration of a phonological form in controls (see Appendix 2, Table A2-1).

JW produced the only whole word exchange error which he attempted to correct: "but J---brought her dad down / dad brought her J---- down in the car" (dad brought J---- down in the car). There were no exchange errors in the control corpus.

Thus only one patient produced a few phonological substitutions, and there was only the most minimal evidence for morpheme movement or exchange errors in the patients' speech. 
Insertions, Anticipations and Perseverations.

There were no differences for the number of Insertions (all $\mathrm{z}<-1.6)$. Patients tended to anticipate more closed class $(\mathrm{P} \mathrm{M}=0.02 \%(0.01), \mathrm{C} \mathrm{M}=0.005 \%(0.01), \mathrm{z}=-1.849, \mathrm{U}=$ $20.00, p=0.064)$, but not open class items $(z<-1.5)$. There was no difference in the number of closed class perseverations $(\mathrm{z}<1.3)$, but patients did perseverate more open class items ( $\mathrm{P}$ $\mathrm{M}=0.23 \%(0.01 \%), \mathrm{C} M=0.04 \%(0.02 \%), \mathrm{U}=13.00, \mathrm{z}=-2.083, \mathrm{p}<0.05)$, see Table 2.

\section{$\underline{\text { Omissions }}$}

Patients tended to omit more open class ( $\mathrm{P} \mathrm{M}=0.72 \%(0.40), \mathrm{C} \mathrm{M}=0.14 \%(0.04)$, $\mathrm{z}=-1.787, \mathrm{U}=14.00, \mathrm{p}=0.074)$ but not closed class items $(\mathrm{z}<-1.1)$. There was no difference in the number of pro-drop omissions $(z<-1.4)$, see Figure 1 and Table 2.

When the prepositions omitted from prepositional phrases (Pp) were compared to those omitted from sub-categorisation ( $\mathrm{Scp}$ ) contexts (as a \% of closed class omissions), patients omitted a greater proportion from Pp contexts (25.5\% (5.64)) when compared to controls (9.4\% (2.52); $\mathrm{U}=10.5, \mathrm{z}=-2.266, \mathrm{p}<0.05)$; the same was not true for $\mathrm{Scp}$ contexts $(\mathrm{P} \mathrm{M}=$ $12.1 \%$ (5.82), $\mathrm{C} \mathrm{M}=5.21 \%$ (2.89), $\mathrm{U}=22.50, \mathrm{z}<-1.0$ ), see Table 3a which gives details of the percentage of omissions constituted by a particular closed or open class subtype. No other comparisons for subtype of closed class omissions were significantly different (all $z<-1.7$ ).

Insert Figure 1 about here

For open class items, there were no differences between the classes (Noun, Verb or Adjective) making up the majority of omissions: see Table 3a. There was no difference in the number of phrasal omissions $(\mathrm{z}<-1.2)$. 


\section{$\underline{\text { Substitutions }}$}

Patients substituted more open class items (P M $=1.45 \%(0.15), \mathrm{C} \mathrm{M}=0.10 \%(0.04), \mathrm{U}=$ $0.00, \mathrm{z}=-3.386, \mathrm{p}<0.005)$. Within nouns, patients had more substitutions of light nouns ( $\mathrm{P} \mathrm{M}$ $=0.74 \%(0.25), \mathrm{C} \mathrm{M}=0.03 \%(0.01), \mathrm{U}=5.50, \mathrm{z}=-2.858 \mathrm{p}<0.01)$ and descriptive noun terms $(\mathrm{P} \mathrm{M}=1.13 \%(0.20 \%), \mathrm{C} \mathrm{M}=0.02 \%(0.02), \mathrm{U}=4.50, \mathrm{z}=-3.085 \mathrm{p}<0.005)$. Within verbs, patients substituted more light verbs $(\mathrm{P} M=0.31 \%(0.06), \mathrm{C} \mathrm{M}=0.03 \%(0.02), \mathrm{U}=$ $6.00, \mathrm{z}=-2.850, \mathrm{p}<0.005)$, see Figure 2. The majority of patients' open class substitution errors involved nouns ( $\mathrm{P} \mathrm{M}=66.4 \%$ (4.14), $\mathrm{C} \mathrm{M}=30.9 \%$ (12.8), $\mathrm{U}=11.5, \mathrm{z}=-2.162$, $\mathrm{p}<0.05)$, see Table $3 \mathrm{~b}$.

Patients also substituted more closed class items ( $\mathrm{P} \mathrm{M}=0.44 \%(0.11), \mathrm{C} \mathrm{M}=0.15 \%(0.02 \%)$, $\mathrm{U}=6.00, \mathrm{z}=-2.731 \mathrm{p}<0.01)$. A greater percentage of the patients' closed class substitutions involved determiners ( $\mathrm{PM}=13.4 \%$ (4.4), $\mathrm{C} \mathrm{M}=0 \%, \mathrm{U}=12, \mathrm{z}=-2.554, \mathrm{p}<0.05)$ and there was a similar tendency to substitute prepositions in Pp contexts $(\mathrm{P} \mathrm{M}=25.0 \%(6.1), \mathrm{C} \mathrm{M}=$ $15.6 \%(12.4), \mathrm{U}=15, \mathrm{z}=-1.864, \mathrm{p}=0.062)$. No other comparisons of this kind were significant. Table $3 \mathrm{~b}$ gives details of the percentage of substitutions constituted by a particular word class subtype, and Appendix 3 provides a detailed break down of substitutions with free-standing closed class items.

Insert Figure 2 and Table 3 about here

\section{Morphological Errors}

These were divided into those errors where a less complicated form was substituted (e.g. 'cry' for 'cried'), labelled as simple, and those where an equally or more complex form was used (e.g. ' "cried' for “cry'), labelled as complex, see Table 2. 
Patients made more complex morphological errors than controls overall $(\mathrm{P} \mathrm{M}=0.08 \%$ (0.01), $\mathrm{C} M=0.01 \%(0.01), \mathrm{U}=5.00, \mathrm{z}=-2.960, \mathrm{p}<0.005)$ and this pattern was maintained, if not stronger, for the subset of errors that occurred with verbs (P M $=0.67 \%(0.22), \mathrm{C} \mathrm{M}=$ $0.0003 \%(0.0003), \mathrm{U}=0.00, \mathrm{z}=-3.508, \mathrm{p}<0.001)$.

There was no difference in the number of simple morphological errors made (All: $\mathrm{P} \mathrm{M}=$ $0.14 \%(0.1), \mathrm{C} \mathrm{M}=0.03 \%(0.01)$; Verbs: $\mathrm{P} \mathrm{M}=1.86 \%(1.53), \mathrm{C} \mathrm{M}=0.0004 \%$ (0.0003); both comparisons $\mathrm{z}<-1.5$ ). For the patients, the majority of simple errors were made by the most impaired individual (DV, 65\%) and as a group controls were more likely to make simple (5/8) rather than complex errors ( $1 / 8$ for verbs only). There was no difference in the number of agreement errors $(\mathrm{P}=0.0016 \%(0.001), \mathrm{C}=0.0017 \%(0.0004) ; \mathrm{z}<-0.5)$. Appendix 4 gives a detailed breakdown of morphological errors in patients.

\section{Planning Errors}

Individual examples are provided in Table 4; see Appendix 2, Tables A2 2 to A2 8for specific examples.

Sentence blends of similar quality and quantity were made by both patients $(n=7)$ and controls $(n=9)$ so patients do not appear abnormal for these errors (see Appendix 2 Table A2 2).

Both groups produced sentences that can be considered semantically or syntactically anomalous, however patients produced considerably more $(n=27)$ in comparison to controls $(\mathrm{n}=11)$. For the controls, a number of these utterances $(8 / 11)$ can be attributed to the misselection of a particular item (see Appendix 2). There were only two sentences that were syntactically malformed, and one instance in which the sentence was semantically 
anomalous/underspecified. For the patients, some of these errors can also be attributed to a similar process of mis-selection, however, even when the offending item has been identified, further restructuring of the sentence is often needed to 'rectify' the utterance. For example, 'It's a frustration with memory people's faces' can become 'It's a problem with memory for people's faces', but it is still better formulated as 'I have a problem remembering people's faces'. Similar to the controls, there were only a couple of instances of frank syntactic violations (see Appendix 2 Table A2 3).

There were a few examples of clear misordering errors, with the same number for both groups. Misordering errors common to both groups were to place the subject and verb last (e.g. 'confident I felt' and 'things like that she did'). Adverbs appeared in various places, which may or may not be considered syntactically anomalous (e.g. 'once a month there' and 'I was allowed to still drive'), so these were not included as errors. There were examples of misordering that appeared for patients but not for controls: putting the verb last on its own, putting a direct object first, moving the negative particle and producing a possessive term after the noun rather than before (see Appendix 2 Table A2 4).

Insert Table 4 about here

Simplified utterances occurred with about equal frequency for patients $(n=7)$ and controls $(n=10)$. As with the semantic and syntactic anomalies, the quality of simplification seemed to differ between groups. For the controls, the majority of utterances were contracted sentences, such that the addition of extra items or inflections would render the sentence normal. For example 'it was a case of / go home and come back again' is better formulated as 'it was a case of / going home and coming back again later on'; similarly, 'and a train from the waist / long train went' could become 'and there was a train from the waist / a long train that went down to the floor' (see Appendix 2 Table A2 5). 
In contrast, simplified utterances from the patients are more semantically ambiguous, and sometimes require the substitution of existing items as well as new items and inflections. For example, 'the sea was coming up' could be 'the tide was coming in' or 'the waves were rising up' and so on. Similarly, 'I was down for ages' could be 'I was knocked down for ages' or 'I was down under the car for ages' and so on. Thus, the lack of detail present in control simplifications is usually due to contracted utterances, rather than a simplification of the entire event as seen in some of the patient utterances. Here, the use of light verbs and prepositions leaves the utterances underspecified and ambiguous. We cannot draw any strong conclusions, as there are similar cases in both patient and control samples, but these sentences do suggest that message generation in the patient group suffers from sparse and degraded information.

Disjointed sentences were common amongst patients, and these kinds of utterances were never produced by controls. These sometimes resulted in a syntactic or semantic anomaly (13/27 utterances, e.g. 'how the hell do I come up / down or not) and suggest that patients have difficulty maintaining correct syntactic or semantic relationships across consecutive utterances (see Appendix 2 Table A2 6).

There were 12 clear examples of approximation or circumlocution (including those that were also semantically or syntactically anomalous) in patients; controls never produced this kind of error. Typically, the sentence fails to express the message in a concise manner, or approximates the intended message through an infelicitous choice of items and sentence structure. These kinds of utterances do reflect a failure to select appropriate and specific items that would allow the message to be expressed in a concise manner, but this failure applies to the entire message rather than a single item (which are evidenced as omission or substitution errors) (see Appendix 2 Table A2 7). 
There were a few examples where patients used a pronoun which had no pre-established discourse referent. As with the disjointed sentences, these errors (which are pragmatic, rather than semantic) demonstrate the difficulty the patients have in maintaining a coherent structure across successive items (see Appendix 2 Table A2 8).

\section{$\underline{\text { Discussion }}$}

Overall SD patients made more errors than controls. They made both substitution and omission errors on open class items but only substitution errors on both free and bound closed class items. There was no evidence of gross syntactic violations, and no increase in agreement errors for patients relative to controls, but the patients' speech did contain some semantic and syntactic anomalies caused by the substitution of inappropriate open class items. There was no evidence of an increased rate of phonological errors.

\section{Message Generation}

SD patients appear to have significant problems translating a pre-verbal message into linguistic structures. The substitutions of light nouns and verbs and descriptive nouns are in line with experimental evidence that specific lexical representations are unavailable or degraded (Hodges \& Patterson, 2007). Patients produced approximately twice as many restarted utterances as controls, indicating an increased incidence of lexical retrieval failures resulting in a complete stop in sentence production. The restarts, simplified utterances, unreferenced pronouns, approximations and circumlocutions support one or both of two possible inferences. One: message level representations are underspecified or noisy, leading to poor translation into syntactic specifications and lexical activation. This follows from 
evidence that the deterioration in SD extends to non-lexical representations, i.e. conceptual information as expressed through modalities such as picture drawing or object use (Bozeat et al, 2000, 2002, 2003). Two: disrupted lexical representations mean that information from the message level cannot be specifically translated. The approximations and descriptive substitutions lend some weight to this inference: patients' utterances can be easily interpreted in context (e.g. 'lovely water places' or 'I effectively you know / helped with his intelligence / to mend the car') but there is a failure to retrieve the appropriate or correct items. Finally, both are real possibilities. Impoverished conceptual representations are likely to produce disrupted lexico-semantic representations (leading to simplifications, unreferenced pronouns, light or general terms, omissions and restarts). In addition, underspecified conceptual representations will fail to support lexical retrieval processes adequately (leading to descriptive substitutions, whole word substitutions, approximations and circumlocutions). Both will cause significant problems both in message generation and in the early stages of lexical retrieval and grammatical encoding.

A further consequence of such impoverished conceptual, message level representations is that local grammatical encoding and global narrative coherence will suffer. There are clear examples of syntactic and semantic anomalies in SD speech that occur more often than in the control sample. Patients appear to garden path themselves into producing errorful sentences. Hierarchical relationships, as expressed in English principally through word order, were correctly maintained. The majority of anomalous utterances were not frank syntactic violations but rather semantically anomalous because of an infelicitous choice of items to express a given meaning. The mis-selected word or phrase could be both semantically and syntactically anomalous. For example, in 'I effectively you know / helped with his intelligence / to mend the car', the infinitival clause 'to mend the car' would be correct if it were a direct complement of the main verb 'help': 'I effectively you know helped [him] to mend the car'. Instead, 'help' first takes an indirect object 'his intelligence' and then the infinitival complement 'to mend the car'. 
The disjointed utterances show substantive problems in planning successive clauses (e.g. 'I went in to / knock on the door / and meet her mum' - 'I knocked on the door and went in to meet her mum'), and the unreferenced terms demonstrate problems that the patients have in maintaining coherent discourse (e.g. 'and that went in didn't it'). This may be partly due to problems with function words that are typically used to link sentences (e.g. through conjunction or subordination), but single clauses were also used erroneously (e.g. 'they bloody did a good job mentally / but physically they weren't'). Thus, it may be the case that SD patients cannot maintain complex, dependent structures; further analyses are underway to assess this hypothesis (Meteyard \& Patterson, in prep). The explanation that fits this - as well as all the other data - is poor translation from the message level to the extended hierarchical structures required for complex sentences. Any problems with complex hierarchical or phrasal processes will be exacerbated by difficulties in lexical retrieval.

Sentence blends were present in both groups. These errors are an intriguing example of processing at the level of sentential planning, with alternative frames selected somewhat holistically. This may be due to a lack of specificity as the message is generated, such that two utterances are coded in parallel and blended together to produce a syntactically incorrect, but easily interpretable, sentence (Bock \& Levelt, 1994). These errors may occur during syntactic encoding processes that are intact in SD (e.g. constituent assembly), so we do not see an increase in their number.

The retrieval of Open Class Items

The patients' problems with lexical retrieval are clearly reflected by their omissions and substitutions of open class words. In particular, they substituted more light nouns (e.g. 'thing', 'stuff'), descriptive noun phrases (e.g. 'lovely water places') and light verbs (e.g. 
'make', 'go', 'have'). The majority of errors that we classified as substitutions were for nouns, probably because it is easier to recognise when a noun has been erroneously substituted (light verbs are often appropriate if used with a phrasal preposition, e.g. compare 'We bought a house in Cambridge' with 'We had a house in Cambridge'). These data confirm anecdotal and clinical observations of the increased use of light and indefinite terms in SD speech, and are in line with experimental evidence that concepts have become degraded by loss of specific, detailed information (e.g. Bozeat et al, 2003). They also lend weight to the idea that as semantic information degrades, light verbs (and nouns) are used more often (Gordon \& Dell, 2003).

The fact that patients perseverated more open class items is in line with an account in which weak activation of target items (due to degraded semantic content) leads to perseveration errors as recently produced items are both retrievable and more active (Martin, Roach, Brecher \& Lowery, 1998). Patients tended to anticipate closed class items more often than controls. No strong conclusions can be drawn from this trend; in combination with the similar omission rates of closed class items for patients and controls, however, it suggests easier retrieval of closed class relative to open class items for the patients. That is, when sentence planning processes encounter difficulties with open class items, available closed class items may emerge prematurely. There was no difference in the number of insertions, which occur when an erroneous item appears with no clear origin in an otherwise correct sentence. Given the effortful nature of lexical retrieval for the patients, it is not surprising that insertions occur within normal rates.

Patients produced open class substitutions approximately 14 times more often than controls and closed class substitutions approximately 3 times more often. Open class omissions occurred approximately 5 times more often but there was no difference in the number of closed class omissions. Thus, substitution is more ubiquitous than omission in SD speech. Given a semantic system with degraded representations that lack specificity, a useful 
compensatory mechanism would select the nearest possible alternative at the coordinate level, or default to a super-ordinate (or ultimately light) term that shares features with the deficient target. A lack of alternative candidates is more likely for open class items that are more individuated, less frequent, less familiar and less predictable than closed class items. Thus, open class items are more likely to be omitted (and the utterance may be restarted). The finding that open class items are more affected than closed class items is also in line with the idea that as semantic information degrades, patients rely on syntactic information to a greater extent (Gordon \& Dell, 2003).

\section{The retrieval of free and bound closed class items}

This study constitutes the first clear evidence in the literature that SD patients have problems with both free and bound closed class morphemes. Patients produced more errors (of all kinds) on closed class words and substituted them significantly more often than controls; in addition, closed class items of all kinds were affected (see Table 3). For example, determiners made up a greater percentage of closed class substitutions for patients; controls never substituted a determiner. Although patients did not omit closed class items more often overall, a division of omissions into subtypes demonstrated that a greater percentage of closed class omissions were prepositions heading prepositional phrases (a similar tendency was seen in closed class substitutions). Patients made more complex morphological errors (particularly on verbs), substituting forms of equal or greater complexity for the correct target. Patients did not differ from controls in the number of agreement errors or in the number of pronouns omitted from the subject position at the start of an utterance (what are termed Pro-Drop omissions).

Under the parsimonious assumption that closed class words and morphological inflections undergo similar competitive selection processes governed by semantic information, one can 
conclude that the semantic deficit does cause problems beyond the selection of open class words. The error patterns suggest that similar processes are at work with open class items and closed class items, both free and bound. Given the preservation of phrasal syntax (as seen by an absence of gross syntactic errors), it also appears that free-standing closed class items were protected when they appeared within a verb phrase (i.e. within verb subcategorisation) rather than as the head of a prepositional phrase. In a similar vein, agreement constraints may have protected closed class substitutions from violating number or person.

As briefly discussed in the introduction, it is possible that problems with closed class items of all kinds arise because the degraded lexico-semantic content of open class items has a knock on effect for the syntactic processes that govern closed class items. This view would imply that syntactic features (e.g. gender, tense) are selected via open class items and that these features govern the selection of closed class items (e.g. gendered determiners, tense marking auxiliaries or inflections). There would thus be no direct connection between semantic information and closed class items. Such a position, however, leaves it unclear why successfully retrieved open class items might still produce problems for the selection of closed class elements. Indeed, the view that closed class elements are primarily syntactic should predict an absence of errors on closed class items in SD speech, as successfully retrieved open class items should have intact lexico-syntactic information, just as they have intact phonology. It is more parsimonious to infer that closed class elements also rely to some degree on semantic information, and are therefore also prone to substitution errors within relatively intact syntactic frames.

Omissions of closed class elements by the patients were within the normal range. Thus, there is a divergence between open class items (which are substituted and omitted) and closed class items and inflections (which are substituted). This difference is parsimoniously explained by the different properties of open and closed class elements (both free and bound). Open class items are by definition a more expansive, differentiated set that are selected to express a specific message; therefore retrieval is more likely to fail catastrophically for open class 
items, despite strategic efforts to substitute an alternative. Closed class elements are limited in number, more frequent and context independent so an alternative is more likely to be available when retrieval fails.

Despite the patients' substitutions of both free and bound closed class items, the number of agreement errors was not significantly different to controls ${ }^{2}$. One might expect that the erroneous use of pronouns, determiners and inflections for person and tense would lead to a higher rate of agreement errors. A closer look at the substitution of closed class items shows how agreement errors were avoided (see Appendix 3 and 4). All determiner errors occurred when possessive pronouns (e.g. my, her, his) were replaced with the simpler determiner 'the'. Thus, there are no instances when agreement with the noun might be a problem. There were a few subject pronoun errors, four instances of the neutral 'it' replacing gendered or other person pronouns, two instances when 'he' and 'she' were swapped, three instances of the demonstrative pronoun 'that' replacing 'it' and one instance of 'they' replacing 'she'. Only the final example in this set might cause a problem for agreement with the verb, and then only in the present tense. Most morphology changes on verbs were confusions of tense (simple past, past participle or past progressive). As patients were talking about their personal histories, it is perhaps not surprising that different forms of the past tense could be confused, particularly if we accept that SD patients have problems maintaining coherent discourse structure. Crucially, tense changes will also typically cause no problems for agreement with subject pronouns.

There does seem to be a tendency for closed class errors to follow constraints that we see in open class errors - the use of more general terms and substitutions of related forms. An interesting possibility is that semantic and syntactic information controlling agreement

\footnotetext{
2 This discussion comes with one caveat: English is a morphologically simple language. The pattern of increased closed class substitutions with no difference in agreement errors may not hold for languages that have more complex agreement.
} 
constrained the closed class substitution errors, just as phrasal syntax protected closed class elements appearing within verb subcategorisation frames. The syntactic marker for a singular pronoun or verb may have prevented the substitution of a plural item, particularly if semantic and morphophonological markers of agreement converged. An increase in agreement errors might surface if sentences were targeted that have a divergence between semantic plurality and morphophonological markers of number (e.g. Eberhard, Cutting \& Bock, 2005). For example, collective nouns such as 'herd' which are morphophonologically singular (having no 's' plural marker) but semantically plural; in such cases SD patients may be more likely to produce sentences such as "the herd is..." as they rely more on morphophological information and interpret these items as singular.

The fact that patients made more errors on both open and closed class items supports a continuity between the two word types (Allen \& Seidenberg, 1999; Goodglass \& Menn, 1985; Plaut \& Shallice, 1993), rather than assigning the selection and representation of closed-class items to syntactic processes (Biassou et al, 1997; Bradley \& Garrett, 1983; Bates \& Wulfeck, 1989; LaPointe \& Dell, 1989). Of particular interest is the semantically shallow nature of closed class elements and their confusability (Allen \& Seidenberg, 1999; Bates \& Wulfeck, 1989). Subtle semantic distinctions (the difference between 'it' and 'that', or between 'on' and 'at') are precisely what one would expect to cause problems when semantic information begins to deteriorate, as in SD.

\section{Phonology}

One patient (PS) accounted for all 8 phonological errors made in the patient group, and he (plus one other patient, BC), were also responsible for all 4 morpheme movement errors. The absence of an increased rate of phonological errors in SD 
speech relative to controls supports previous evidence that phonological processing is preserved in SD (Jefferies et al., 2005; Majerus, Norris \& Patterson, 2007; Patterson \& MacDonald, 2006).

It might be argued that SD patients should produce more phonological errors, even in conversational speech. Multiple phonological representations are activated during lexical retrieval and, under the assumptions of the Semantic Binding Hypothesis, semantic information interacts with these representations to prevent phoneme movement across words. Because SD patients have a weak and/or noisy semantic system, such semantic constraints should be reduced. As explained in the Introduction, this reduction in semantic binding with its consequence of a high rate of phonological errors is readily observed when the patients perform auditory-verbal short-term memory tasks. We argue that it would not, on the whole, be expected to occur in spontaneous speech where the patients are only producing words that either (a) still have reasonably strong semantic representations, or (b) occur in rather stereotyped contexts/phrases. On the other hand, we acknowledge that the paucity of phonological errors in our corpus may be the result of a floor effect for patients as well as controls, and that more taxing questions/topics might elicit a modest increase of such errors in the patients' speech. Either way, our results support the argument that, when semantic information is stable enough to support lexical retrieval, phonological processing proceeds normally (e.g. Garrett, 1982; 1984) and the processes that serialise and order phonological constituents are intact in SD. 


\section{Conclusion}

The canonical view of fluent and grammatically correct speech in SD is only partially supported by our results. Whilst there was no evidence of gross syntactic violations, there was definitely an increased rate of errors on free and bound closed class items, and syntactic anomalies occurred when lexical retrieval went awry. We end with the twin questions of why the syntax of SD speech might (a) be relatively preserved and (b) appear, on casual observation, to be even more normal than it actually is. Syntax is abstracted information and it is likely to be redundantly coded (Bates \& Wulfeck, 1989) as it applies across all members of a given class and across variations in other semantic content. Given that the semantic deficit in SD is so strongly modulated by redundant coding - i.e. what the patients still know is information that generalises to many different concepts (Patterson, 2007; Rogers \& Patterson, 2007) - it seems plausible that lexico-syntactic information may be precisely the kind of abstracted, general, highly frequent information that should be preserved in SD. Syntactic structures can be seen as highly routinised and automatically produced (Bates \& Wulfeck, 1989; Kempler, Curtiss \& Jackson, 1987) and the processes that underpin their use in production have been constructively compared to implicit learning (Bock \& Griffin, 2000; Chang, Dell \& Bock, 2006; Ferriera \& Bock, 2006).

Evidence suggests that SD Patients become increasingly reliant on implicit, procedural memory processes as conceptual-semantic memory deteriorates (e.g. Graham et al, 2000). If syntactic processing relies on highly redundant, abstract, frequent lexico-syntactic information in combination with production processes with the characteristics of implicit learning, we might not expect to see gross syntactic problems in the conversational speech of patients with SD. Indeed, phrasal syntax was remarkably preserved in the face of substitutions errors for both open and closed class items. Anecdotal and clinical observations suggest that SD patients do fall back on routinized phrases, filler terms and a familiar vocabulary (Bird et al, 2000). This suggests that as the diseases progresses, syntax may become affected in a similar manner to lexico-semantics: a reduction in complexity and 
variation, and reliance on highly frequent and familiar information that is still available. This may not draw attention because of the nature of most normal conversational speech: the majority of utterances (around 70\%) are simple, one-participant clauses and light verb use is very common (Thompson \& Hopper, 2001). The speech samples we used were taken from fairly unconstrained, informal interviews. The patients were not asked to produce particular structures or vocabulary, and would naturally have employed any strategies available that allowed them to speak fluently and normally. In other words, problems with complex syntax may not be apparent because patients - and people in general - rarely produce such structures in free speech.

\section{References}

Allen, J., \& Seidenberg, M. S. (1999). The emergence of grammaticality in connectionist networks. In B. MacWhinney (Ed.), The emergence of language (pp. 115-152). Mahwah, NJ: Lawrence Erlbaum.

Altmann, L. J. P. (2004). Constrained sentence production in probable Alzheimer's disease. Applied Psycholinguistics, 25, 145-173.

Altmann, L. J. P., Kempler, D., \& Andersen, E. S. (2001). Speech Errors in Alzheimer's Disease: Reevaluating Morphosyntactic Preservation. Journal of Speech, Language and Hearing Research, 44, 1069-1082.

Bates, E., \& Wulfeck, B. (1989). Crosslinguistic studies of aphasia. In B. MacWhinney \& E. Bates (Eds.), The crosslinguistic study of sentence processing (pp. 328-371). Cambridge, UK.: Cambridge University Press.

Benedet, M., Patterson, K., Gomez-Pastor, I., \& Garcia de la Rocha, M. L. (2006). "Non-semantic" aspects of language in semantic dementia: As normal as they're said to be? Neurocase, 12(1526).

Biassou, N., Obler, L. K., Nespoulous, J.-L., Dordain, M., \& Harris, K. S. (1997). Dual Processing of Open- and Closed-Class Words. Brain and Language, 57, 360-373.

Bird, H., Lambon Ralph, M. A., Patterson, K., \& Hodges, J. R. (2000). The rise and fall of frequency and imageability: Noun and verb production in semantic dementia. Brain and Language, 73(17-49). 
Bock, K. (1982). Toward a Cognitive Psychology of Syntax: Information Processing Contributions to Sentence Formulation. Psychological Review, 89(1), 1-47.

Bock, K. (1986). Meaning, Sound and Syntax: Lexical priming in sentence production. Journal of Experimental Psychology: Learning, Memory and Cognition., 12(4), 575-586.

Bock, K. (1987). An effect of accessibility of word forms on sentence production. Journal of Experimental Psychology: Learning, Memory and Cognition., 12, 575-586.

Bock, K. (1999). Language Production. In R. Wilson \& F. Keil (Eds.), MIT encyclopedia of the cognitive sciences (pp. 453-456). Cambridge, MA.: MIT Press.

Bock, K., \& Levelt, W. (1994). Language Production: Grammatical Encoding. In M. A. Gernsbacher (Ed.), Handbook of Psycholinguistics (pp. 945-984). San Diego: Academic Press.

Bock, K., \& Warren, R. K. (1985). Conceptual accessibility and syntactic structure in sentence formulation. Cognition, 21, 47-67.

Bozeat, S., Lambon Ralph, M. A., Garrard, P., Patterson, K., \& Hodges, J. R. (2000). Non-verbal semantic impairment in semantic dementia. Neuropsychologia, 38, 1207-1215.

Bozeat, S., Lambon Ralph, M. A., Graham, K. S., Patterson, K., Wilkin, H., Rowland, J., et al. (2003). A duck with four legs: Investigating the structure of conceptual knowledge using picture drawing in semantic dementia. Cognitive Neuropsychology, 20(1), 27-47.

Bozeat, S., Lambon Ralph, M. A., Patterson, K., \& Hodges, J. R. (2002). When objects lose their meaning: What happens to their use? Cognitive, Affective, \& Behavioral Neuroscience, 2(3), 236-251.

Bradley, D. C., \& Garrett, M. F. (1983). Hemisphere differences in the recognition of closed and open class words. Neuropsychologia, 21(2), 155-159.

Brown, R., \& McNeill, D. (1966). The "tip of the tongue" phenomenon. Journal of Verbal Learning and Verbal Behavior, 5, 325-337.

Caramazza, A., Miozzo, M., Costa, A., Schiller, N. O., \& Alario, F.-X. (2001). A Crosslinguistic Investigation of Determiner Production. In E. Dupoux \& J. Mehler (Eds.), Language, Brain, and Cognitive Development: Essays in Honor of Jacques Mehler (pp. 209-225). Cambridge, MA.: MIT Press.

Chang, F., Bock, K., \& Goldberg, A. E. (2003). Can thematic roles leave traces of their places? Cognition, 90(1), 29-49.

Chang, F., Dell, G. S., \& Bock, K. (2006). Becoming Syntactic. Psychological Review, 113(2), 234272.

Cutler, A. (1981). The reliability of speech error data. Linguistics, 19, 560-582.

Dell, G. S. (1986). A spreading activation theory of retrieval in language production. Psychological Review, 93(283-321).

Druks, J., \& Froud, K. (2002). The syntax of single words: Evidence from a patient with a selective function word reading deficit. Cognitive Neuropsychology, 19(3), 207-244.

Eberhard, K.M., Cutting, J.C. \& Bock, K. (2005) Making Syntax of Sense: Number Agreement in Sentence Production. Psychological Review, 112(3), 531-559.

Ferreira, V. S., \& Bock, K. (2006). The functions of structural priming. Language and Cognitive Processes, 21(7-8). 
Ferreira, V. S., \& Humphreys, K. R. (2001). Syntactic Influences in Lexical and Morphological Processing in Language Production. Journal of Memory and Language, 44, 52-80.

Folstein, M. F., Folstein, S. E., \& McHugh, P. R. (1975). Mini-mental state: A practical guide for grading the mental state of patients for the clinician. Journal of Psychiatric Research, 12, 189198.

Fromkin, V. A. (1971). The non-anomalous nature of anomalous utterances. Language, 47, 27-52.

Garrett, M. F. (1975). The Analysis of Sentence Production. In G. H. Gower (Ed.), The Psychology of Learning and Motivation (Vol. 9). New York: Academic Press.

Garrett, M. F. (1980). Levels of Processing in Sentence Production. In B. Butterworth (Ed.), Language Production. Volume 1: Speech and Talk. London: Academic Press.

Garrett, M. F. (1982). Production of speech: Observations from normal and pathological language use. In A. W. Ellis (Ed.), Normality and pathology in cognitive functions (pp. 19-76). London: Academic Press.

Garrett, M. F. (1984). The organisation of processing structure for language production: applications to aphasic speech. In D. Caplan, A. R. Lecours \& A. Smith (Eds.), Biological perspectives on language (pp. 172-193). London: MIT Press.

Garrett, M. F. (1990). Sentence Processing. In D. Osherson \& H. Lasnik (Eds.), Invitation to Cognitive Science. Cambridge, MA.: MIT Press.

Goldrick, M. (2006). Limited interaction in Speech Production. Language and Cognitive Processes, 21(7-8), 817-855.

Goodglass, J., \& Menn, L. (1985). Is agrammatism a unitary phenomenon? In M. L. Kean (Ed.), Agrammatism. New York: Academic Press.

Gordon, B., \& Caramazza, A. (1985). Lexical access and frequency sensitivity: Frequency saturation and open/closed class equivalence. Cognition, 21, 95-115.

Gordon, J.K. \& Dell, G.S. (2003) Learning to divide the labor: an account of deficits

in light and heavy verb production. Cognitive Science, 27, 1-40.

Graham, K. S., Simons, J. S., Pratt, K. H., Patterson, K., \& Hodges, J. R. (2000). Insights from semantic dementia on the relationship between episodic and semantic memory. Neuropsychologia, 38, 313-324.

Hodges, J. R., \& Patterson, K. (1995). Is semantic memory consistently impaired early in the course of Alzheimer's disease? Neuroanatomical and diagnostic implications. Neuropsychologia, 33, 441-459.

Hodges, J. R., \& Patterson, K. (2007). Semantic dementia: a unique clinicopathological syndrome. Lancet Neurology, 6, 1004-1014

Hodges, J. R., Patterson, K., Oxbury, S., \& Funnell, E. (1992). Semantic dementia: Progressive Fluent aphasia with temporal lobe atrophy. Brain, 115, 1783-1806.

Hornberger, M., Piguet, O., \& Hodges, J. R. (2008, 02/09-05/09/2008). Autobiographical Memory Profiles in Semantic Dementia. Paper presented at the First Meeting of the Federation of the European Societies of Neuropsychology, Edinburgh.

Jefferies, E., Jones, R., Bateman, D., \& Lambon Ralph, M. A. (2005). A semantic contribution to nonword recall? Evidence for intact phonological processes in semantic dementia. Cognitive Neuropsychology, 22(2), 183-212. 
Kempler, D., Curtiss, S., \& Jackson, C. (1987). Syntactic Preservation in Alzheimer's Disease. Journal of Speech and Hearing Research, 30, 343-350.

Kopelman, M. D., Wilson, B. A., \& Baddeley, A. D. (1990). The autobiographical memory interview. Bury St Edmunds: Thames Valley Test Company.

La Heij, W., Mak, P., Sander, J., \& Willeboordse, E. (1998). The gender-congruency effect in pictureword tasks. Psychological Research, 61(209-219).

Lambon Ralph, M. A., \& Patterson, K. (2008). Generalization and differentiation in semantic memory: Insights from semantic dementia. Annals of the New York Academy of Sciences, 1124, 61-76.

LaPointe, S. G. (1985). A thoery of verb form use in the speech of agrammatic aphasics. Brain and Language, 24, 100-155.

LaPointe, S. G., \& Dell, G. S. (1989). A synthesis of some recent work in sentence production. In G. N. Carlson \& M. K. Tanenhaus (Eds.), Linguistic structure in language processing. Dordrecht, the Netherlands.: Kluwer Academic Publishers.

Levelt, W., \& Maassen, B. (1981). Lexical Search and Order of Mention in Sentence Production. In W. Klein \& W. Levelt (Eds.), Crossing the Boundaries in Linguistics (pp. 221-252). Dordrecht: Reidel Publishing Company.

Levelt, W. J. M., Roelofs, A., \& Meyer, A. S. (1999). A theory of lexical access in speech production. Behavioral and Brain Sciences, 22, 1-75.

Levine, B., Svoboda, E., Hay, J. F., Winocour, G., \& Moscovitch, M. (2002). Aging and Autobiographical Memory: Dissociating Episodic From Semantic Retrieval. Psychology and Aging, 17(4), 677-689.

MacKay, D. G., Burke, D. M., \& Stewart, R. (1998). H.M.'s Language Production Deficits: Implications for Relations between Memory, Semantic Binding, and the Hippocampal System. Journal of Memory and Language, 38, 28-69.

Majerus, S., Norris, D., \& Patterson, K. (2007). What does a patient with semantic dementia remember in verbal short-term memory? Order and sound but not words. Cognitive Neuropsychology, 24(2), 131-151.

Martin, N., Roach, A., Brecher, A. \& Lowery, J. (1998) Lexical retrieval mechanisms underlying whole-word perseveration errors in anomic aphasia. Aphasiology, 12(4/5), 319-333.

Mathuranath, P. S., Nestor, P., Berrios, G. E., Rakowicz, W., \& Hodges, J. R. (2000). A brief cognitive test battery to differentiate AD and FTD. Neurology, 55, 1613-1620.

McKinnon, M. C., Miller, B., Black, S., Moscovitch, M., \& Levine, B. (2006). Autobiographical memory in semantic dementia: Implications for theories of limbic-neocortical interactions in remote memory. Neuropsychologia, 44(12), 2421-2429.

Menn, L., \& Obler, L. K. (1990). Agrammatic Aphasia: A Cross-Linguistic Narrative Sourcebook. (Vol. Volumes I, II \& III.). Amsterdam: John Benjamins Publishing Co.

Mesulam, M. M., Grossman, M., Hillis, A., Kertesz, A., \& Weintraub, S. (2003). The Core and Halo of Primary Progressive Aphasia and Semantic Dementia. Annals of Neurology, 54, s11-s14.

Milman, L. H., Dickey, M. W., \& Thompson, C. K. (2008). A psychometric analysis of functional category production in English agrammatic narratives. Brain and Language, 105(1), 18-31.

Nestor, P., Graham, K. S., Bozeat, S., Simons, J. S., \& Hodges, J. R. (2002). Memory consolidation and the hippocampus: Further evidence from studies of autobiographical memory in semantic 
dementia and frontal variant frontotemporal dementia. Neuropsychologia, 40(6), 633-654.

Nickels, L., \& Howard, D. (2000). When the words won't come: Relating impairments and models of spoken word production. In L. R. Wheeldon (Ed.), Aspects of Language Production. Hove, UK.: Psychology Press.

Osterrieth, P. (1994). Le test de copie d'une figure complexe. Archives de Psychologie, 30, 205-220.

Patterson, K. (2007). The reign of typicality in semantic memory. Philosophical Transactions of the Royal Society B, 362, 813-821.

Patterson, K., Graham, N., \& Hodges, J. R. (1994). The Impact of Semantic Memory Loss on Phonological Representations. Journal of Cognitive Neuroscience, 6(1), 57-69.

Patterson, K., Lambon Ralph, M. A., Hodges, J. R., \& McClelland, J. L. (2001). Deficits in irregular past-tense verb morphology associated with degraded semantic knowledge.

Neuropsychologia, 39(7), 709-724.

Patterson, K., Lambon Ralph, M. A., Jefferies, E., Woollams, A. M., Jones, R., Hodges, J. R., et al. (2006). "Presemantic" Cognition in Semantic Dementia: Six Deficits in Search of an Explanation. Journal of Cognitive Neuroscience, 18, 169-183.

Patterson, K., \& MacDonald, M. C. (2006). Sweet nothings: Narrative speech in semantic dementia. In S.Andrews (Ed.), From Inkmarks to Ideas: Current issues in lexical processing (pp. 299-317). Hove, UK.: Psychology Press.

Plaut, D. C., \& Shallice, T. (1993). Deep Dyslexia: A Case Study of Connectionist Neuropsychology. Cognitive Neuropsychology, 10(5), 377-500.

Poirier, M. \& St. Aubin (1996) Immediate serial recall, word frequency, item identity and item position. Canadian Journal of Experimental Psychology [Revue Canadienne de Psychologie Experimentale], 50, 408-412.

Roelofs, A. (2004). Error Biases in Spoken Word Planning and Monitoring by Aphasic and Nonaphasic Speakers: Comment on Rapp and Goldrick (2000). Psychological Review, 111(2), 561-572.

Rogers, T. T., \& Patterson, K. (2007). Object Categorization: Reversals and Explanations of the BasicLevel Advantage. Journal of Experimental Psychology: General., 136(6), 451-469.

Rogers, T. T., Patterson, K., \& Graham, K. S. (2007). Colour knowledge in semantic dementia: It is not all black and white. Neuropsychologia, 45(14), 3285-3298.

Rosen, H. J., Gorno-Tempini, M. L., Goldman, W. P., Perry, R. J., Schuff, N., Weiner, M., et al. (2002). Patterns of brain atrophy in frontotemporal dementia and semantic dementia. Neurology, 58(198-208).

Schiller, N. O., \& Caramazza, A. (2002). The Selection of Grammatical Features in Word Production: The Case of Plural Nouns in German. Brain and Language, 81(81), 342-357.

Schiller, N. O., \& Caramazza, A. (2003). Grammatical feature selection in noun phrase production: Evidence from German and Dutch. Journal of Memory and Language, 48(1), 169-194.

Schiller, N. O., \& Caramazza, A. (2006). Grammatical gender selection and the representation of morphemes: The production of Dutch diminutives. Language and Cognitive Processes, 21 (78), 945-978.

Schiller, N. O., \& Costa, A. (2006). Different Selection Principles of Freestanding and Bound Morphemes in Language Production. Journal of Experimental Psychology: Learning, Memory and Cognition., 32(5), 1201-1207. 
Schriefers, H. (1993). Syntactic processes in the production of noun phrases. Journal of Experimental Psychology: Learning, Memory and Cognition., 19(841-850).

Schriefers, H., Jescheniak, J. D., \& Hantsch, A. (2005). Selection of gender-marked morphemes in speech production. Journal of Experimental Psychology: Learning, Memory and Cognition., 31, 159-168.

Seeley, W. W., Bauer, A. M., Miller, B. L., Gorno-Tempini, M. L., Kramer, J. H., Weiner, M., et al. (2005). The natural history of temporal variant frontotemporal dementia. Neurology, 64, 13841390.

Snowden, J. S., Neary, D., \& Mann, D. M. (1996). Fronto-Temporal Lobar Degeneration: FrontoTemporal Dementia, Progressive Aphasia, Semantic Dementia. New York: Churchill Livingstone.

Thompson, S. A., \& Hopper, P. J. (2001). Transitivity, clause structure, and argument structure: Evidence from conversation. In J. Bybee \& P. Hopper (Eds.), Frequency and the Emergence of Linguistic Structire (Vol. 45). Amsterdam/Philadelphia: John Benjamins Publishing Company.

Treiman, R. \& Danis, C. (1988) Short-term memory errors for spoken syllables are affected by the linguistic structure of the syllables. Journal of Experimental Psychology: Learning, Memory and Cognition. 14(1):145-52.

Tyler, LK, Moss, HE, Patterson, K \& Hodges, JR (1997). The gradual deterioration of syntax and semantics in a patient with progressive aphasia. Brain \& Language, 56, 426-476.

Vigliocco, G., Antonini, T., \& Garrett, M. F. (1997). Grammatical gender is on the tip of Italian tongues. Psychological Science, 8(4), 314-317.

Vigliocco, G., \& Hartsuiker, R. J. (2002). The interplay of meaning, sound, and syntax in sentence production. Psychological Bulletin, 128, 442-472.

Vigliocco, G., \& Kita, S. (2006). Language-specific properties of the lexicon: Implications for learning and processing. Language and Cognitive Processes, 21(7-8), 261-280.

Walker, I. \& Hulme, C. (1999) Concrete words are easier to recall than abstract words : Evidence for a semantic contribution to short-term serial recall. Journal of Expeirmental Psychology: Learning, Memory and Cognition, 25(5), 1256-1271.

Walsh Dickey, M., \& Thompson, C. K. (2007). The relation between syntactic and morphological recovery in agrammatic aphasia: A case study. Aphasiology, 21(6-8), 604-616.

Warrington, E. K. (1975). The selective impairment of semantic memory. Quarterly Journal of Experimental Psychology, 27, 635-657.

Woollams, A. M., Cooper-Pye, E., Hodges, J. R., \& Patterson, K. (2008). Anomia: A doubly typical signature of semantic dementia. Neuropsychologia, 2503-2514. 
Figure 1: Percentage Omission Errors on Open and Closed Class Words*

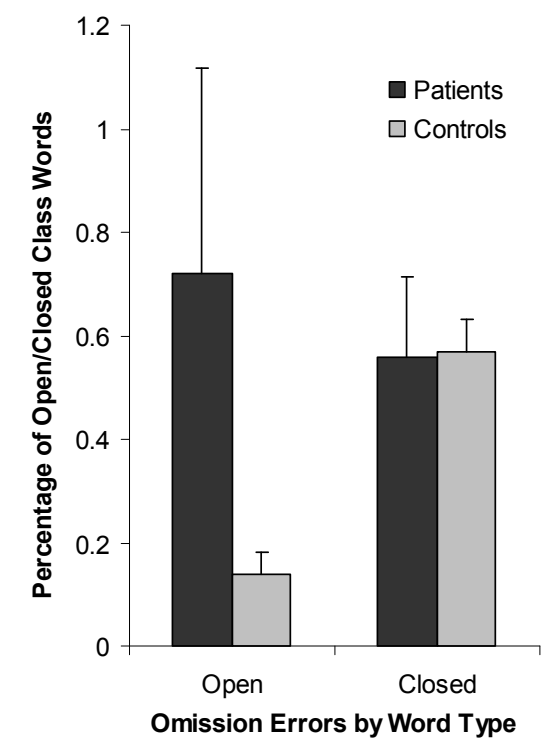

*Error bars are one Standard Error

Figure 3: Percentage Substitution Errors on Open and Closed Class Words, Nouns and Verbs.

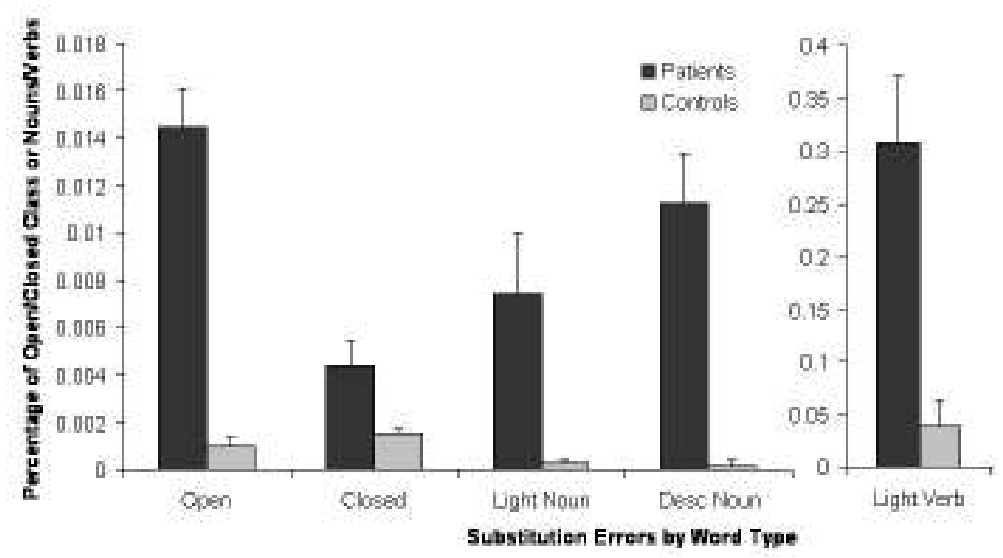

*Error bars are one Standard Error 
$\underline{\text { Table 2: Mean values and group comparisons for experimental measures }}{ }^{\dagger}$

\begin{tabular}{|c|c|c|c|c|}
\hline Measure & Proportion & Patients & Controls & Comparison \\
\hline MLU & words/utterance & $4.8(0.31)$ & $6.6(0.25)$ & $\mathrm{z}=-3.125 * *$ \\
\hline All Errors & $\%$ utterances & $23.8 \%(2.9)$ & $7.0 \%(0.58)$ & $\mathrm{z}=-3.361 * *$ \\
\hline Corrections & $\%$ errors & $8.2 \%(1.9)$ & $16.2 \%(4.8)$ & $\mathrm{z}<-1.2$ \\
\hline $\begin{array}{l}\text { Open Class } \\
\text { Errors }\end{array}$ & $\%$ open class & $25 \%(2.8)$ & $0.5 \%(0.1)$ & $\mathrm{z}=-3.361 * *$ \\
\hline $\begin{array}{l}\text { Closed Class } \\
\text { Errors } \\
\end{array}$ & $\%$ closed class & $30 \%(1.9)$ & $1.3 \%(0.1)$ & $\mathrm{z}=-3.361 * *$ \\
\hline Restarts & $\%$ utterances & $8.7 \%(1.72)$ & $4.27 \%(0.88)$ & $\mathrm{z}=-2.1 *$ \\
\hline \multicolumn{5}{|l|}{ Insertion } \\
\hline Open Class & $\%$ open class & $0.0003 \%(0.0002)$ & nil & $\mathrm{z}<-1.5$ \\
\hline Closed Class & $\%$ closed class & $0.002 \%(0.0006)$ & $0.0007 \%(0.00024)$ & $z<-1.6$ \\
\hline \multicolumn{5}{|l|}{ Anticipation } \\
\hline Open Class & $\%$ open class & $0.0001 \%(0.00005)$ & $0.0005 \%(0.00021)$ & $\mathrm{z}<-1.5$ \\
\hline Closed Class & $\%$ closed class & $0.02 \%(0.01)$ & $0.005 \%(0.01)$ & $\mathrm{z}=-1.849, \mathrm{p}=0.064$ \\
\hline \multicolumn{5}{|l|}{ Perseveration } \\
\hline Open Class & $\%$ open class & $0.23 \%(0.01)$ & $0.04 \%(0.02)$ & $\mathrm{z}=-2.083 *$ \\
\hline Closed Class & $\%$ closed class & $0.0006 \%(0.0002)$ & $0.0002 \%(0.0001)$ & $\mathrm{z}<-1.3$ \\
\hline
\end{tabular}

Omissions

\begin{tabular}{lllll}
\hline Open Class & $\%$ open class & $0.72 \%(0.4)$ & $0.14 \%(0.04)$ & $\mathrm{z}=-1.787, \mathrm{p}=0.074$ \\
\hline Closed Class & $\%$ closed class & $0.56 \%(0.15)$ & $0.57 \%(0.06)$ & $\mathrm{z}<-1.1$ \\
\hline Pro Drop & $\%$ closed class & $0.0075 \%(0.002)$ & $0.012 \%(0.002)$ & $\mathrm{z}<-1.5$ \\
\hline
\end{tabular}

Substitutions

\begin{tabular}{lllll}
\hline Open Class & \% open class & $0.44 \%(0.11)$ & $0.15 \%(0.02)$ & $\mathrm{z}=-2.731^{*}$ \\
\hline Closed Class & \% closed class & $1.45 \%(0.15)$ & $0.10 \%(0.04)$ & $\mathrm{z}=3.386^{* *}$ \\
\hline Desc. Nouns & $\%$ nouns & $0.074 \%(0.003)$ & $0.0003 \%(0.00013)$ & $\mathrm{z}=-3.085^{* *}$ \\
\hline Light Nouns & $\%$ nouns & $0.0113 \%(0.002)$ & $0.0002 \%(0.0002)$ & $\mathrm{z}=-2.858^{* *}$ \\
\hline Light Verbs & $\%$ verbs & $0.31 \%(0.063)$ & $0.039 \%(0.026)$ & $\mathrm{z}=-2.850 * *$ \\
\hline
\end{tabular}

Morphology

\begin{tabular}{lllll}
\hline All Complex & $\%$ all words & $0.077 \%(0.012)$ & $0.01 \%(0.01)$ & $\mathrm{z}=-2.96^{* *}$ \\
\hline All Simple & $\%$ all words & $0.14 \%(0.95)$ & $0.03 \%(0.01)$ & $\mathrm{z}<-1.1$ \\
\hline Verb Complex & $\%$ verbs & $0.67 \%(0.22)$ & $0.0003 \%(0.0003)$ & $\mathrm{z}=-3.508^{* *}$ \\
\hline Verb Simple & $\%$ verbs & $1.86 \%(1.53)$ & $0.0004 \%(0.0003)$ & $\mathrm{Z}<-1.5$ \\
\hline & & & \\
Agreement & $\%$ utterances & $0.0016 \%(0.001)$ & $0.0017 \%(0.0004)$ & $\mathrm{z}<-0.5$ \\
\hline
\end{tabular}

$\dagger$ brackets are one standard error, all comparisons are Mann Whitney U tests.

* significant at $\mathrm{p}<0.05$

$* *$ significant at $\mathrm{p}<0.005$ 
Table 3: (a) Omissions and (b) Substitutions broken down by mean percentage subtype.

\begin{tabular}{lll}
\hline Error and item type & $\begin{array}{l}\text { Group } \\
\text { Patients }\end{array}$ & Controls $\S$ \\
\hline
\end{tabular}

\begin{tabular}{|c|c|c|}
\hline \multicolumn{3}{|l|}{$\begin{array}{l}\text { (a) Omissions } \\
\text { Closed Class }\end{array}$} \\
\hline Pronoun & $6.88(11.5)$ & $5.625(8.40)$ \\
\hline Preposition (Pp) & $25.46(15.95)^{*}$ & $9.39(7.13)$ \\
\hline Preposition (Scp) & $12.05(16.46)$ & $5.21(8.19)$ \\
\hline Conjunction & $8.51(10.25)$ & $8.57(10.11)$ \\
\hline Determiner & $33.46(19.4)$ & $57.90(28.95)$ \\
\hline Auxilliary & $6.7(8.20)$ & $5.65(6.62)$ \\
\hline Other† & $6.91(11.39)$ & $7.63(19.45)$ \\
\hline \multicolumn{3}{|l|}{ Open Class } \\
\hline Noun & $46.7(31.79)$ & $54.9(40.17)$ \\
\hline Verb & $51.25(31.4)$ & $45.17(40.17)$ \\
\hline Adjective & $2.1(5.94)$ & 0 \\
\hline
\end{tabular}

(b) Substitutions

\begin{tabular}{lll} 
Closed Class & \\
\hline Pronoun & $21.38(23.1)$ & $19.79(35.05)$ \\
\hline Preposition (Pp) & $24.99(17.12)$ & $15.625(35.19)$ \\
\hline Preposition (Scp) & $19.10(19.3)$ & $22.9(36.66)$ \\
\hline Conjunction & $7.5(7.85)$ & $13.54(19.89)$ \\
\hline Determiner & $13.4(12.44)^{*}$ & 0 \\
\hline Auxilliary & $4.75(5.49)$ & $21.875(24.77)$ \\
\hline Other† & $8.8(14.00)$ & $6.25(17.68)$ \\
\hline & & \\
Open Class & & $49.5(33.94)$ \\
\hline Noun & $66.43(11.7)^{*}$ & $50.47(33.94)$ \\
\hline Verb & $32.18(12.6)$ & 0 \\
\hline Adjective & $1.3(0.68)$ & \\
\hline
\end{tabular}

Standard deviation in brackets. Percentages are closed class subtype for closed class errors, and open class subtype for open class errors.

* Value for Patients is significantly greater than for Controls.

$\uparrow$ Negatives, modifiers, quantifiers, comparatives, conditionals, numbers, see Appendix 1. $\S$ For Open Class errors the table averages do not include Controls who did not make either omission or substitution errors on any open class items. Statistical comparisons included all participants. 
Table 1: Standard test scores for the SD patients*

\begin{tabular}{|c|c|c|c|c|c|c|c|c|c|c|c|c|c|}
\hline \multicolumn{2}{|c|}{ Participants } & \multicolumn{2}{|c|}{ Age/Sex } & \multicolumn{10}{|c|}{ Measures } \\
\hline & & $A g e^{*}$ & Sex & $\begin{array}{l}\text { ACE } \\
(/ 100)\end{array}$ & $\begin{array}{l}\text { MMSE } \\
(/ 30)\end{array}$ & $\begin{array}{l}\text { Digit } \\
\text { Span } \\
\text { (back) }\end{array}$ & $\begin{array}{l}\text { Rey } \\
\text { Copy } \\
(/ 36)\end{array}$ & $\begin{array}{l}\text { CCT } \\
\text { Pictures } \\
(/ 64)\end{array}$ & $\begin{array}{l}\text { Word- } \\
\text { Picture } \\
\text { matching. } \\
\text { (/64) }\end{array}$ & $\begin{array}{l}\text { Summed } \\
\text { Letter } \\
\text { Fluency } \\
(F, A, S)\end{array}$ & $\begin{array}{l}\text { Summed } \\
\text { Category } \\
\text { Fluency } \\
\text { (Animals, } \\
\text { Fruit, Birds) }\end{array}$ & $\begin{array}{l}\text { Object } \\
\text { Naming } \\
(/ 64)\end{array}$ & $\begin{array}{l}\text { Production } \\
\text { Score (sum } \\
\text { of fluency } \\
\text { and naming } \\
\text { scores) }\end{array}$ \\
\hline Control & & 64.5 & $3 \mathrm{M}, 11 \mathrm{~F}$ & 92.7 & 29 & 5.4 & 34.2 & $56.9 \dagger$ & 64 & 45 & 51 & 62.3 & 158.3 \\
\hline \multirow{8}{*}{ Patients } & $D V$ & 68.7 & $\bar{M}$ & 28 & 16 & 5 & 35.5 & 20 & 2 & 10 & 0 & 1 & 11 \\
\hline & $J C$ & 60.1 & $M$ & 47 & 20 & 4 & 34 & 48 & 50 & 6 & 4 & 14 & 24 \\
\hline & $P S$ & 58.9 & $M$ & 61 & 27 & 5 & 36 & 45 & 48 & 21 & 6 & 23 & 50 \\
\hline & $M J$ & 71.1 & $M$ & 59 & 26 & 6 & 34 & 32 & 49 & 12 & 15 & 36 & 63 \\
\hline & $\mathrm{GH}$ & 58.9 & $M$ & 63 & 26 & 4 & 36 & 42 & 55 & 22 & 20 & 42 & 84 \\
\hline & $J W$ & 75.7 & $\mathrm{M}$ & 66 & 27 & 4 & 36 & 47 & 55 & 38 & 21 & 30 & 89 \\
\hline & $B C$ & 60.4 & $M$ & 70 & 28 & 6 & 35 & 39 & 51 & 41 & 10 & 41 & 92 \\
\hline & $D B$ & 65.2 & $\mathrm{M}$ & 81 & 25 & 6 & 36 & 56 & 63 & 36 & 19 & 58 & 113 \\
\hline
\end{tabular}

*at time of completing the majority of tests; the ACE, MMSE and Category Fluency scores are the most recent scores available. Patients are ordered top to bottom according to decreasing severity (on the basis of a combined production score). †Control mean taken from Bozeat et al (2000).

Abbreviations and references: ACE, Addenbrooke's cognitive examination (Mathuranath et al., 2000); MMSE, Mini-Mental State Examination (Folstein et al., 1975); Rey Copy, Rey-Osterrieth complex figure test (Osterrieth, 1944); CCT, Camel and Cactus Test (Bozeat et al, 2000); Word-Picture matching (Hodges \& Patterson, 1995); Control values were taken from a large sample of healthy elderly subjects (reported in Hodges and Patterson, 1995). 
Table 4: Number of Planning errors in Patients and Controls with examples for each type*

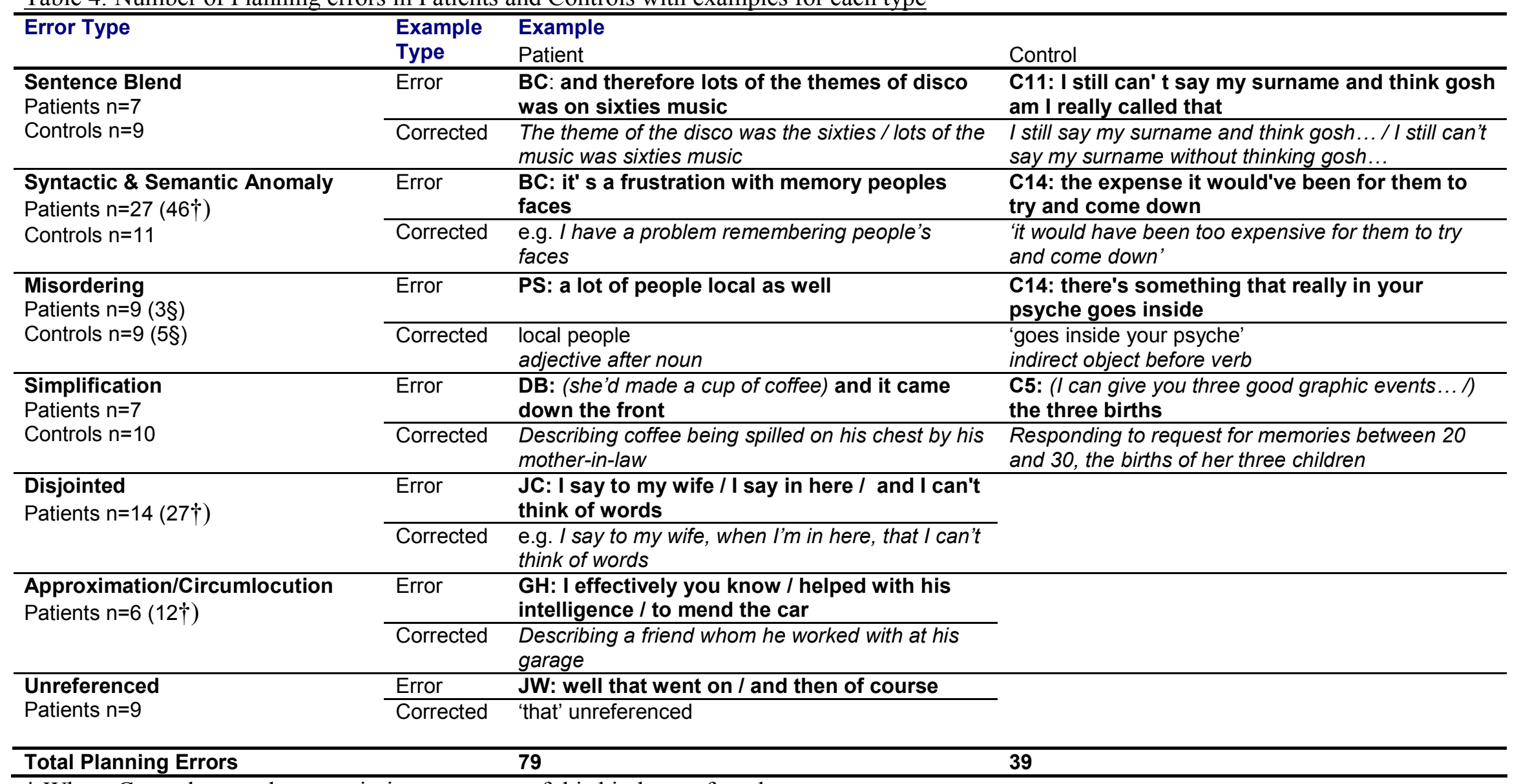

* Where Control examples are missing, no errors of this kind were found

$\dagger$ number when include those cross-classified as Syntactically/Semantically anomalous and some other planning error type.

$\S$ Questionable status as an error / acceptable in conversation, e.g. adverb movement. 